\title{
Odontomas in Early Childhood: A Rare Presentation of Compound Odontomas in Primary Dentition
}

\author{
Mohamed Salim ${ }^{1 *}$, Amal Ahmed ${ }^{2}$, Dana Ahmed ${ }^{2}$, Mohamed Abdelmalik Mahadi ${ }^{3}$ and Mohammed Alhadad MA ${ }^{4}$ \\ ${ }^{1}$ Senior Resident of OMFS, Arab Board Program, Military Hospital, Division of OMFS, Sudan \\ ${ }^{2}$ Internship at the Ministry of Health, Sudan \\ ${ }^{3}$ Specialist at Military Hospital, Division of OMFS, Sudan \\ ${ }^{4}$ Senior Consultant at Military Hospital, Division of OMFS, Dean of the Faculty of Dentistry, Karary University, Sudan
}

Submission: March 29, 2021; Published: April 08, 2021

*Corresponding author: Mohamed Salim, Senior resident of OMFS, Military hospital, Sudan

Abstract

Odontomas are the most common odontogenic tumors. odontomas have been classified as a benign tumor, more as a hamartomata's mass rather than a neoplastic one. Morphologically divided into subgroups, complex and compound odontomas. it appears most likely in the permanent dentition with higher incidence in the anterior maxillary region and posterior mandible. it may cause multiple impactions, retention of primary teeth and malocclusion as a future consequence. in extreme cases of large sized odontomas, it may be accompanied by multiple infections and serious complications. we present two cases of compound odontomas associated with primary dentition which is exceedingly rare.

Keywords: Odontomas; Hamartoma; Primary dentition

\section{Introduction}

Odontomas are one the most common developmental anomalies that affect the oral cavity [1]. These tumors are formed of enamel, dentin, and some variables like cementum and pulp tissues [2]. During the development of the tumor, enamel and dentin were deposited in a way similar anatomically to normal tooth structure, in which it is called compound odontomas. However, when it forms irregular forms of tooth structures it is then called complex odontomas [2]. Here, we report two cases of similar presentation of compound odontomas in the right maxillary canine region.

\section{Case No. 1}

5 years old male came to our department complaining of delayed eruption and painless swelling noticed by his parents two weeks ago in the right incisor-canine region of the maxilla. his parents denied any history of trauma at the site of the lesion. his past medical history of no clinical significance. both pre and postnatal periods were normal. this was his first dental visit. No history of similar condition in his family. On examination, extra- orally, slightly diffused swelling in the right side of midface, causing asymmetry. intraorally, multiple carious anterior maxillary teeth with missing upper right maxillary primary canine. Well defined painless swelling with normal overlying mucosa, hard in consistency, extend from primary lateral incisor to primary first molar of the same site, with buccal expansion, normal temperature, non-pulsatile (Figure 1a). Periapical and OPG showed irregular radio-opacities with central radiolucencies (teeth like structures) in the right maxillary canine area (Figure 1b). Our diagnosis was based on clinical and radiographic findings as compound odontoma. Surgical removal of the lesion was done under general anesthesia (Figure 1c). The lesion consists of several tooth-like structures and was sent for histopathological assessment (Figure 1d). Diagnosis was confirmed by oral pathologist as compound odontoma.

\section{Case No. 2}

4 years old female came to our department complaining of delayed eruption of teeth and a painful swelling noticed one month ago in the right maxillary anterior region, no history of trauma or 
previous infection at the site of the lesion. Normal pre and postnatal periods. Parents mentioned the child was unvaccinated. This was her first dental visit. no similar condition in her family history. On examination, a slight swelling in the right area superior to the upper lip, causing asymmetry extra-orally. Intra-orally, a tender swelling in the right anterior maxillary region, hard in texture, normal overlying mucosa, with buccal expansion, non-pulsatile with normal temperature with absence of primary canine (Figure 2a). Periapical view was done, and it showed multiple calcified teeth like structures with scattered radiolucencies (Figure 2b). Same as case 1, our diagnosis was compound odontoma. surgical removal of the lesion was done under GA (Figure 2c). It showed more teeth like structures compared to case 1 (Figure $2 \mathrm{~d}$ ).

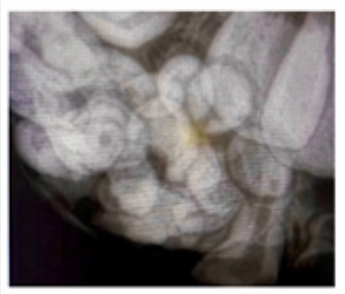

Figure 1a

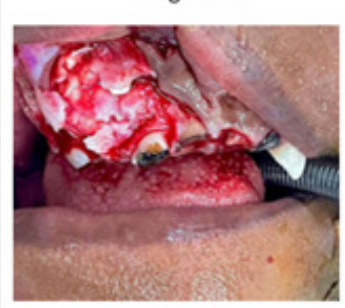

Figure 1c

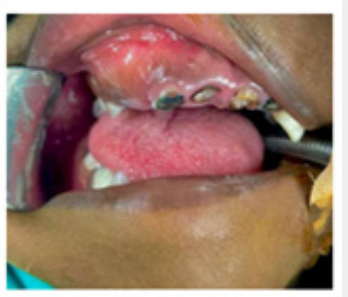

Figure 1b

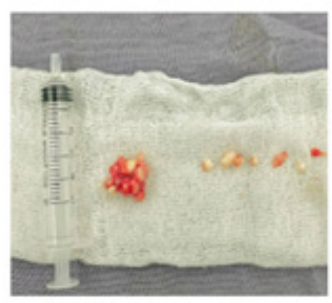

Figure 1d

Figure 1: 1a. Right maxillary canine area, 1b. Buccal expansion, normal temperature, non-pulsatile, 1c. Surgical removal of the lesion was done under general anesthesia, 1d. Lesion consists of several tooth-like structures and was sent for histopathological assessment.

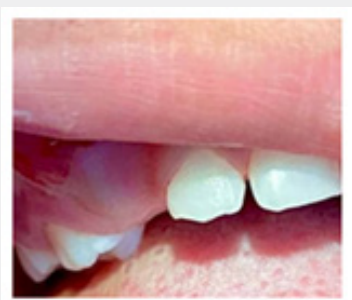

Figure 2a

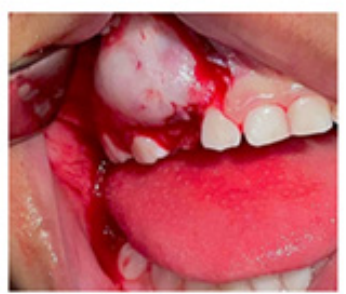

Figure 2c

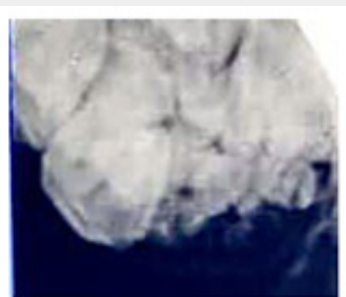

Figure 2b

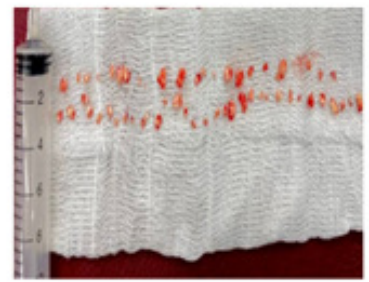

Figure 2d

Figure 2: 2a. Buccal expansion, non-pulsatile with normal temperature with absence of primary canine, $2 \mathrm{~b}$. Multiple calcified teeth like structures with scattered radiolucencies, 2c. Surgical removal of the lesion was done under GA, 2d. Teeth like structures compared to case 1 .

\section{Discussion}

Odontomas are tumors which are formed of enamel, dentin, and some variables like cementum and pulp tissues. During the development of the tumor enamel and dentin were deposited in a way similar anatomically to normal tooth structure, in which it called compound odontoma. however, when it forms irregular 


\section{Advances in Dentistry \& Oral Health}

form of tooth structure it is then called complex odontoma. Many authors describe this lesion as hamartoma rather than true neoplasm [3]. It can occur anywhere in the dental arch, most likely anterior maxillary region for compound subtype and molar region for the complex odontoma [4]. Summary of cases diagnosed is shown in Table 1 [5]. Generally, it is a painless slowly growing mass which vary in sizes, ranging from few millimeters into multiple centimeters, and when it reaches a huge size it may cause expansion of the cortical bone $[2,6]$. The etiology of odontoma is unknown but many suggestions such as trauma, and infections at the site of occurrence are considered $[7,8]$.

Table 1: Summary of cases diagnosed.

\begin{tabular}{|c|c|c|c|}
\hline Age of Patients & Location & Type of Odontoma & Publication \\
\hline 4-year-old & Maxillary & Compound & Axel [10] \\
\hline 4-year-old & Maxillary & Compound & Aimes [11] \\
\hline 3-year, 6-month-old & Maxillary & Compound & Aimes [12] \\
\hline 4-year-old & Mandibular & Complex & Hitchin \& White [13] \\
\hline 4-year, 11-month-old & Maxillary & Compound & Hitchin \& Dekonor [14] \\
\hline 8-year, 7-month-old & Maxillary & Compound & Hitchin \& Dekonor [14] \\
\hline 5-year-old & Maxillary & Compound & Noonan [15] \\
\hline 6-year-old & Maxillary & Compound & Stajcic [3] \\
\hline 2-year-old & Maxillary & Not Stated & Brunetto et al. [9] \\
\hline 1 year, 2-month-old & Maxillary & Compound & Haishima et al. [16] \\
\hline 1 year, 8-month-old & Maxillary & Compound & Haishima et al. [16] \\
\hline 3 year, 6-month-old & Maxillary & Compound & Bacetti [17] \\
\hline 3-year-old & Maxillary & Compound & Olivero et al. [18] \\
\hline 30-month-old & Maxillary & Compound & Long et al. [19] \\
\hline 3-year-old & Maxillary & Complex & Motokawa et al. [8] \\
\hline 4-year-old & Maxillary & Compound & Yassin [20] \\
\hline 2 year, 5-month-old & Maxillary & Compound & Yeung et al. [21] \\
\hline 4 year, 8-month-old & Maxillary & Complex & Sheehy et al. [22] \\
\hline
\end{tabular}

Odontomas occur mainly in permanent dentition with very few reports that have mentioned the occurrence of such lesions in the primary dentition. Impaction of teeth is most common in permanent dentition, although rarely it may happen in deciduous teeth $[9,10]$. multiple causes of eruption failure such as mechanical lock by tumors or genetic disorders (cleidocranial dysplasia) are encountered [10-12]. In our cases the cause of absence of the primary canine is compound odontoma. radiographic assessment was done by periapical views and OPG. Surgical removal was done under general anesthesia and both samples were confirmed clinically and histologically as compound odontoma. Recurrence rate is extremely rare [13-15]. In both cases presented in this paper, the primary canines were difficult to preserve and therefore extracted. After that patients were referred to pediatric dentistry department for space management if needed.

\section{Conclusion}

Early detection of such lesions with proper surgical management will be of a great benefit to prevent future complications such as malocclusion and psychological impact of facial asymmetry for the patient and his guardians. Multidisciplinary approach is also preferable for management of odontomas in pediatric population by involving pedodontics with special interest in interceptive orthodontics.

\section{References}

1. De Oliveira BH, Campos V, Marçal S (2001) Compound odontomadiagnosis and treatment: three case reports. Pediatr dent 23(2): 151157.

2. Neville BW, Damm DD, Allen CM, Chi AC (2015) Oral and maxillofacial pathology. Elsevier Health Sciences p. 13.

3. Sheehy EC, Odell EW, Al-Jaddir G (2004) Odontomas in the primary dentition: literature review and case report. J Dent Child 71(1): 73-76.

4. Stajcic ZZ (1988) Odontoma associated with a primary tooth. J pedod 12(4): 415-420.

5. Yildirim-Öz G, Tosun G, Kiziloḡlu D, Durmuș E, Șener Y (2007) An unusual association of odontomas with primary teeth. European journal of dentistry 1(1): 045-049.

6. Cawson RA, Binnie WH, Eveson JW (1994) Color atlas of oral disease: Clinical and pathologic correlations. Wolfe.

7. Shafer WG, Hine MK, Levy BM (1983) A Textbook of Oral Pathology, $4^{\text {th }}$ Ed. Saunders Philadelphia: Pennsylvania, USA pp. 308-311.

8. López-Areal L, Donat FS, Lozano JG (1992) Compound odontoma erupting in the mouth: 4-year follow-up of a clinical case. J Oral pathol Med 21(6): 285-258. 
9. Yeung $\mathrm{KH}$, Cheung RC, Tsang MM (2003) Compound odontoma associated with an unerupted and dilacerated maxillary primary central incisor in a young patient. Int J Paediatr Dent 13(3): 208-212.

10. Otsuka Y, Mitomi T, Tomizawa M, Noda T (2001) A review of clinical features in 13 cases of impacted primary teeth. Int J Paediatr Dent 11(1): 57-63.

11. Snawder KD (1974) Delayed eruption of the anterior primary teeth and their management: report of a case. ASDC J Dent Child 41(5): 382-384.

12. Motokawa W, Braham RL, Morris ME, Tanaka M (1990) Surgical exposure and orthodontic alignment of an unerupted primary maxillary second molar impacted by an odontoma and a dentigerous cyst: A case report. Quintessence Int 21(2): 159-162.
13. O'Sullivan EA (2000) Multiple dental anomalies in a young patient: a case report. Int J Paediatr Dent 10(1): 63-66.

14. Yassin OM (1999) Delayed eruption of maxillary primary cuspid associated with compound odontoma. J Clin Pediatr Dent 23(2): 147149.

15. Dunn RH, Roberts WL, DeBoom GW (1939) Well-circumscribed, radiopaque, and radiolucent lesion of the anterior maxilla. Journal of the American Dental Association 118(4): 467-468.

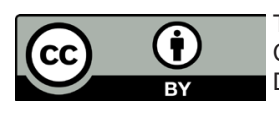

This work is licensed under Creative Commons Attribution 4.0 License DOI: 10.19080/ADOH.2021.14.555879

\section{Your next submission with Juniper Publishers} will reach you the below assets

- Quality Editorial service

- Swift Peer Review

- Reprints availability

- E-prints Service

- Manuscript Podcast for convenient understanding

- Global attainment for your research

- Manuscript accessibility in different formats ( Pdf, E-pub, Full Text, Audio)

- Unceasing customer service

Track the below URL for one-step submission https://juniperpublishers.com/online-submission.php 